\title{
Corrosion Inhibition of Carbon Steel in Hydrochloric Acid Solution by Mentha Pulegium Extract
}

\author{
A. Khadraoui, ${ }^{a, *}$ A. Khelifa, ${ }^{a}$ H. Boutoumi, ${ }^{a}$ B. Mettai, ${ }^{b}$ \\ Y. Karzazi, ${ }^{c, d}$ B Hammouti ${ }^{c, *}$ \\ a Laboratoire de Génie chimique, Département de Génie des Procédés, Faculté de \\ Technologie, Université de Blida I, BP 270, Route de Soumaâ, 09000, Blida, Algérie \\ ${ }_{b}$ Centre de Recherche et Développement, BP 194, Bouchaoui, 16000, Alger, Algérie \\ c LACE-URAC18, Faculty of Sciences, University Mohammed Premier, \\ B.P. 4808, 60046 Oujda, Morocco \\ d National School of Engineering and Applied Sciences, University Mohammed Premier, \\ B.P. 3, 32003 Sidi Bouafif, ENSA Al Hoceima, Morocco
}

Received 15 June 2014; accepted 21 August 2014

\begin{abstract}
The inhibition effect of Mentha pulegium extract (MPE) on the acid corrosion of carbon steel in $1 \mathrm{M} \mathrm{HCl}$ solution was investigated using weight loss, potentiodynamic polarisation, and electrochemical impedance spectroscopy. The results show that the Mentha pulegium extract is a good inhibitor, and that the inhibition efficiency depends on the concentration of the plant extract. Efficiency is higher than $88 \%$ for $33 \%$ Mentha pulegium extract. Polarization measurements also show that Mentha pulegium extract is a good mixed inhibitor. The remarkable inhibition efficiency of MPE was discussed in terms of blocking of the electrode surface by adsorption of inhibitor molecules through active centres. Mentha pulegium extract is adsorbed on the carbon steel surface according to the Temkin adsorption model. The effect of temperature on the corrosion behaviour of carbon steel in $1 \mathrm{M} \mathrm{HCl}$ with addition of 33\% MPE was studied in the temperature range 308-338 K. SEM also confirmed the adsorption of MPE on carbon steel surface.
\end{abstract}

Keywords: Mentha pulegium; Green Inhibitor; Adsorption; SEM; Carbon steel.

\section{Introduction}

Natural products were previously used as corrosion inhibitors for different metals in various environments $[1,2]$ and their optimum concentrations were reported.

\footnotetext{
*Corresponding author. E-mail address: hammoutib@gmail.com; khadraoui.abdelkader@gmail.com
} 
The obtained data showed that plant extracts could serve as effective corrosion inhibitors and they have become important because they are environmentally acceptable, readily available and renewable sources for a wide range of needed inhibitors. Plant extracts are viewed as an incredibly rich source of naturally synthesized chemical compounds that can be extracted by simple procedures with low cost. The extracts from the leaves, seeds, heartwood, bark, roots and fruits of plants have been reported to inhibit metallic corrosion in acidic media [3-5].

It has been established that the inhibitory actions of plant extracts are due to the presence of some organic compounds such as saponin, tannin, alkaloid, steroids, glycosides, and amino acids [6-10]. Most of these compounds have centers for $\pi$ electrons and functional groups which provide electrons that facilitate the adsorption of the inhibitor on the metal surface. Also, the presence of hetero atoms such as $\mathrm{N}, \mathrm{P}, \mathrm{O}$, and $\mathrm{S}$ enhances the adsorption (which is the initial mechanism of inhibition) of the inhibitor on the metal surface [11-22].

In Algeria, collection of medicinal and aromatic plants to extract, after distillation, essential oils for the manufacture of cosmetics, pharmaceuticals as well as flavors for food products, is a virgin field. The distillation of plants is sufficiently known, but remains largely untapped, despite the availability in Algeria of large tracts of forests and fields, whose territory covers important plant resources distributed on the coasts, plains, mountains, steppes, the Sahara and around water points.

Mentha pulegium can be used as a corrosion inhibitor for carbon steel. It is a native and perennial aromatic herb of the Mediterranean region, but it is widely growing in many parts of the world in temperate and tropical countries; Mentha pulegium is a species of flowering plant in the family Lamiaceae. The leaves exhibit a very strong fragrance similar to spearmint. It is a traditional culinary herb, folk remedy, and abortifacient. Mentha pulegium are sources of diverse classes of natural compounds such as flavonoids, alkaloids, essential oils [23].

In the present work, the inhibitive action of Mentha pulegium extract (MPE) as a cheap, eco-friendly and naturally occurring substance on the corrosion behavior of carbon steel in $1 \mathrm{M} \mathrm{HCl}$ has been investigated through weight loss measurements, potentiodynamic polarization and electrochemical impedance spectroscopy (EIS) methods and surface analyses.

\section{Experimental procedure}

\section{Plant collection and extraction}

Mentha pulegium was collected during June 2009 in Ain-defla, north Algeria, at $280 \mathrm{~m}$ altitude. The aerial parts of the plant were air-dried in the laboratory at room temperature. Stock solutions of the plant extract were prepared by extracting weighed amounts of the powder of the dried leaves for 3 days in $1 \mathrm{M}$ $\mathrm{HCl}$ (Merck) at $298 \mathrm{~K}$ with continuous agitation. The solution was filtered and stored. 
The filtrates from both acid extractions had a reddish-brown appearance. From the stock solutions, inhibitor test solutions were prepared in the concentration range $1-50 \%(\mathrm{v} / \mathrm{v})$.

\section{Weight loss measurements}

Coupons cut into $(2 \times 1.5 \times 0.2) \mathrm{cm}^{3}$ dimensions having composition $(0.13 \% \mathrm{C}$, $0.32 \% \mathrm{Si}, 0.64 \% \mathrm{Mn}, 0.15 \% \mathrm{Cu}, 0.012 \% \mathrm{~S}, 0.01 \% \mathrm{P}, 0.038 \% \mathrm{Al}, 0.081 \% \mathrm{Cr}$, $0.011 \% \mathrm{Mo}, 0.083 \% \mathrm{Ni}, 0.01 \% \mathrm{~V}$ and Fe balance) are used for weight loss measurements. Prior to all measurements, the exposed area was mechanically abraded with 280, 400, 600, 800, 1200 grades of emery papers. The specimens are washed thoroughly with bidistilled water, degreased and dried with ethanol before being weighed and immersed in $60 \mathrm{~mL}$ of the corrosive medium. The immersion time for the weight loss measurements was 6 hours at $298 \mathrm{~K}$.

\section{Electrochemical tests}

The electrochemical study was carried out using an EG\&G potensiostat/ galvanostat (PAR 273A) piloted by CORR III software. This potentiostat is connected to a cell, with three electrodes, thermostats with double wall. A saturated calomel electrode (SCE) and a platinum electrode were used as reference and auxiliary electrodes, respectively. The material used for constructing the working electrode was the same used for gravimetric measurements. The surface area exposed to the electrolyte is $0.64 \mathrm{~cm}^{2}$. Potentiodynamic polarization curves were plotted at a polarization scan rate of $1 \mathrm{mV} / \mathrm{s}$. Before all experiments, the potential was stabilized at free potential during $30 \mathrm{~min}$. The polarization curves are obtained from $-750 \mathrm{mV}$ to $250 \mathrm{mV}$ at $298 \mathrm{~K}$. The solution test has been done after de-aerated by bubbling nitrogen. Gas bubbling is maintained prior and through the experiments. The data in Tafel region have been processed for evaluation corrosion kinetic parameters by plotting the polarization curves. The linear Tafel segments, in a large domain of potential, of the cathodic curves were extrapolated to the corresponding corrosion potentials to obtain the corrosion current values.

The electrochemical impedance spectroscopy (EIS) measurements are carried out with the Analyzer of function of transfer model 5210, piloted by Powersuite software. After the determination of the steady-state current at a corrosion potential, sine wave voltage $(10 \mathrm{mV})$ peak to peak, at frequencies between $100 \mathrm{kHz}$ and $10 \mathrm{mHz}$ are superimposed on the rest potential. Computer programs automatically controlled the measurements performed at rest potentials after $30 \mathrm{~min}$ of exposure at $298 \mathrm{~K}$. The impedance diagrams are given in the Nyquist representation. Experiments are repeated three times to ensure the reproducibility.

\section{Results and discussion}

\section{Gravimetric measurements}

The effect of the addition of Mentha pulegium extract (MPE) tested at different concentrations on the corrosion of carbon steel in $1 \mathrm{M} \mathrm{HCl}$ solution was studied 
using weight-loss method at $298 \mathrm{~K}$ after $6 \mathrm{~h}$ of immersion period. Inhibition efficiency $\mathrm{E}(\%)$ is calculated as follows:

$$
E(\%)=\left(\frac{\text { Wcorr- W'corr }}{\text { Wcorr }}\right) 100
$$

where $\mathrm{W}_{\text {corr }}$ and $\mathrm{W}_{\text {corr }}^{\prime}$ are the corrosion rate of carbon steel in $1 \mathrm{M} \mathrm{HCl}$ in absence and presence of the inhibitor, respectively.

Table 1 gives values of the rate of corrosion $\left(\mathrm{mg} \mathrm{cm} \mathrm{cm}^{-2} \mathrm{~h}^{-1}\right.$ and inhibition efficiency $(\mathrm{E} \%)$ for corrosion of carbon steel in $1 \mathrm{M} \mathrm{HCl}$ in the presence of mentha pulegium extract as green inhibitor at different concentrations.

Table 1. Gravimetric results of the carbon steel corrosion with and without addition of MPE after $6 \mathrm{~h}$ of immersion in $1 \mathrm{M} \mathrm{HCl}$ at $298 \mathrm{~K}$.

\begin{tabular}{ccc}
\hline System & $\mathbf{W}\left(\mathbf{m g} / \mathbf{c m}^{\mathbf{2}} \mathbf{h}\right)$ & $\mathbf{E}(\boldsymbol{\%})$ \\
Blank & 0.1693 & $/$ \\
$6.25 \%$ & 0.1049 & 38.04 \\
$12.5 \%$ & 0.0820 & 51.55 \\
$25 \%$ & 0.0620 & 63.36 \\
$33 \%$ & 0.0295 & 82.54 \\
\hline
\end{tabular}

From Table 1, it's clear that the corrosion rate of carbon steel in the blank is higher in comparison with the blank containing MPE. The $\mathrm{W}$ decreased when the concentration of inhibitors increased. The addition of $6.25 \%$ mentha pulegium extract into the aggressive medium reduces the corrosion rate by $38 \%$, reaching $82.54 \%$ with the addition of $33 \%$ of mentha pulegium extract. The inhibition efficiency of mentha pulegium extracts increases as a function of their concentration. This result suggests that an increase in extract concentration increases the number of inhibitor molecules adsorbed onto the carbon steel surface and reduces the surface area that is available for the direct acid attack on the metal surface.

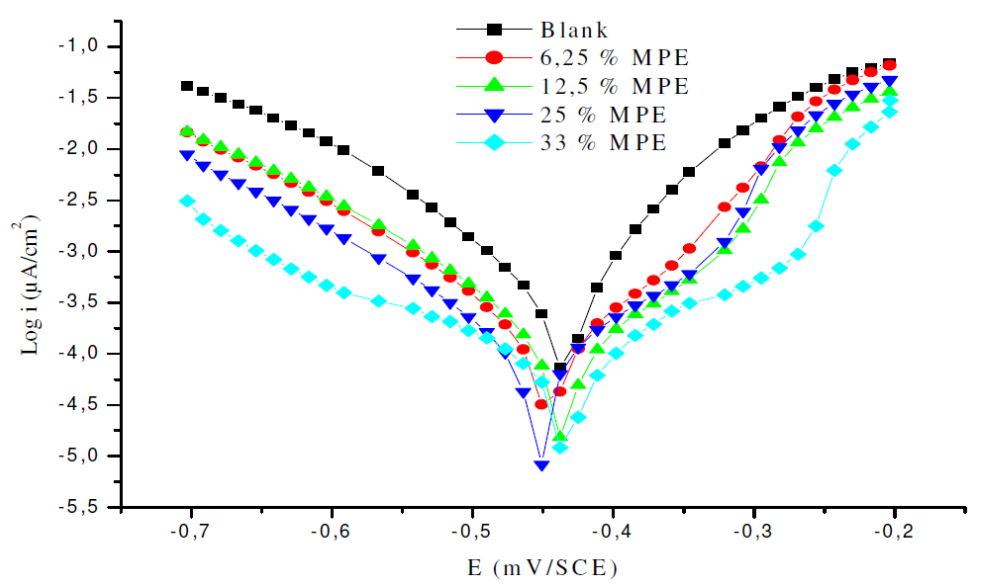

Figure 1. Potentiodynamic polarisation curves for carbon steel in $1 \mathrm{M} \mathrm{HCl}$ in the presence of different concentrations of plant extract (MPE). 


\section{Polarization curves}

Potentiodynamic polarization curves of carbon steel in molar $\mathrm{HCl}$ in the absence and presence of MPE at different concentrations at $298 \mathrm{~K}$ are presented in Fig. 1. From this figure, it can be seen that with the increase of the extract concentrations, both anodic and cathodic currents were inhibited. This result shows that the addition of the Mentha pulegium inhibitor reduced anodic dissolution and also retarded the hydrogen evolution reaction.

In addition, the parallel cathodic Tafel curves in Fig. 1 show that the hydrogen evolution is activation controlled, and the reduction mechanism is not affected by the presence of the plant extract [24].

Table 2 shows the fitting results of the polarization curves obtained. Other electrochemical parameters and the inhibition efficiencies of the extract can be determined from the corrosion current densities $\left(i_{\text {corr }}\right)$ with and without inhibitors, which are also presented in Table 2.

Table 2. Electrochemical data for steel in $1 \mathrm{M} \mathrm{HCl}$ in the absence and presence of different concentrations of Mentha pulegium extract, and the corresponding inhibition efficiency.

\begin{tabular}{ccccc}
\hline System & $\begin{array}{c}\mathbf{E}_{\text {corr }} \\
(\mathbf{m V} / \mathbf{S C E})\end{array}$ & $\begin{array}{c}\mathbf{I}_{\text {corr }} \\
\left(\boldsymbol{\mu A} \mathbf{A} / \mathbf{c m}^{\mathbf{2}}\right)\end{array}$ & $\begin{array}{c}\boldsymbol{\beta}_{\mathbf{c}} \\
(\mathbf{m V} / \mathbf{d e c})\end{array}$ & $\begin{array}{c}\mathbf{E} \\
(\boldsymbol{\%})\end{array}$ \\
Blank & -504 & 422.3 & 115.4 & - \\
$6.25 \%$ & -497 & 220.9 & 140.7 & 47.69 \\
$12.5 \%$ & -499 & 208.1 & 141 & 50.72 \\
$25 \%$ & -501 & 133.6 & 138 & 68.63 \\
$33 \%$ & -500 & 49.22 & 144.5 & 88.34 \\
\hline
\end{tabular}

In this case, the inhibition efficiency is defined as follows:

$$
\mathrm{E} \%=\left(1-\frac{\mathrm{I}_{\text {corr }}^{\prime}}{\mathrm{I}_{\text {corr }}}\right) 100
$$

where $I_{\text {corr }}$ and $I_{\text {corr }}$ are current densities in absence and presence of MPE, respectively. We noted that $\mathrm{I}_{\text {corr }}$ and $\mathrm{I}_{\text {corr }}$ were calculated from the intersection of cathodic and anodic Tafel lines.

The inspection of results in Table 2 indicates that the inhibition efficiency of the Mentha pulegium extract is $88 \%$; the free corrosion potential determined after 30 $\mathrm{mn}$ of immersion does not change in the presence of the green inhibitor; thus, it can be classified as a mixed-type inhibitor in $1 \mathrm{M} \mathrm{HCl}$.

\section{Electrochemical impedance spectroscopy measurements}

EIS has been shown to be a powerful tool to study the corrosion processes of metals in different environments and to characterize the inhibition ability of a corrosion inhibitor, which is related to the charge transfer resistance $\left(R_{t}\right)$. The double-layer capacitance- $\left(\mathrm{C}_{\mathrm{dl}}\right)$ can also be used to determine the inhibition ability. The inhibition performance of an organic or natural substance on a metal surface depends not only on the chemical structure of the organic substance and the nature of the metal, but also on the experimental conditions such as the immersion time and the concentration of the adsorbent. 
The corrosion behavior of carbon steel, in acidic solution with and without Mentha pulegium extract, is also investigated by electrochemical impedance spectroscopy (EIS) measurements at 298 K (Fig. 2).

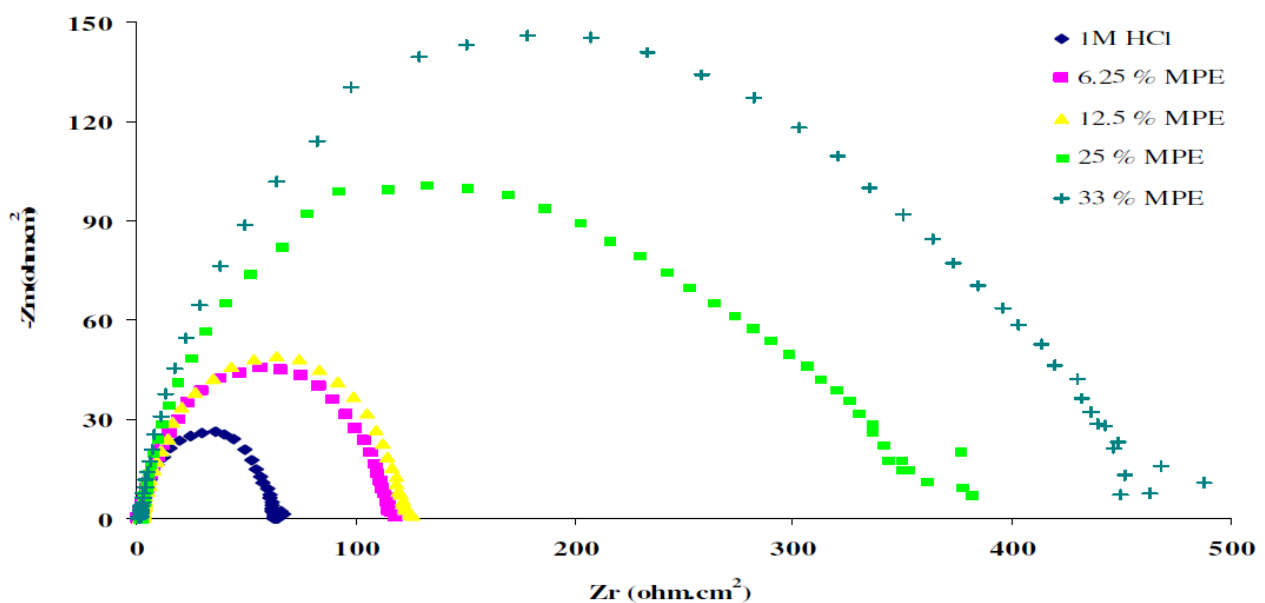

Figure 2. Nyquist plots of steel in $1 \mathrm{M} \mathrm{HCl}$ with and without different concentrations of Mentha pulegium extract at $298 \mathrm{~K}$.

The electrochemical impedance parameters derived from these investigations are mentioned in Table 3.

Table 3. Impedance parameters for corrosion of carbon steel in $1 \mathrm{M} \mathrm{HCl}$ in the absence and presence of different concentrations Mentha Pulegium extract at 298 K.

\begin{tabular}{ccccc}
\hline System & $\left.\mathbf{R t}(\boldsymbol{\Omega . c m})^{2}\right)$ & $\mathbf{E}(\boldsymbol{\%})$ & $\mathbf{f}_{\text {max }}(\mathbf{H z})$ & $\mathbf{C}_{\mathbf{d l}}\left(\mathbf{n} \mathbf{F} / \mathbf{c m}^{2}\right)$ \\
\hline Blank & 62.63 & $/$ & 25.82 & 98.46 \\
$6.25 \%$ & 116.8 & 46.37 & 45.39 & 30.03 \\
$12.5 \%$ & 122.2 & 48.74 & 49.08 & 26.55 \\
$25 \%$ & 207.7 & 69.84 & 100.81 & 7.60 \\
$33 \%$ & 457.3 & 86.30 & 146.01 & 2.38 \\
\hline
\end{tabular}

The inhibition efficiency got from the charge transfer resistance is calculated by:

$$
E \%=\left(\frac{R_{t}-R_{t}^{\circ}}{R_{t}}\right) 100
$$

where $R_{t}$ and $R_{t}^{0}$ are the charge transfer resistances in inhibited and uninhibited solutions respectively.

The charge transfer resistance $\left(R_{t}\right)$ values are calculated from the difference in impedance at lower and higher frequencies, as suggested by Tsuru et al. [25].

As it can be seen from Fig. 2, impedance diagrams show a semi-circular appearance, indicating that a charge transfer process mainly controls the corrosion of carbon steel. From the impedance data, we notice an increase in the charge transfer resistance and decrease of the double layer capacitance with increasing the inhibitor concentration, indicating that Mentha pulegium extract inhibits the corrosion rate of carbon steel by an adsorption mechanism. Therefore, the decrease in the $\mathrm{C}_{\mathrm{dl}}$ value can be attributed to a decrease in the 
local dielectric constant and/or an increase in the thickness of the electrical double layer, suggesting that the inhibitor molecules act by adsorption at the metal/solution interface as a consequence of the replacement of water molecules by the inhibitor molecules [26].

A comparison may be made between the inhibition efficiency $\mathrm{E}(\%)$ values obtained by different methods (weight loss and electrochemical methods).We can see that whatever the method used, no significant changes are observed in E (\%) values. We can then conclude that there is a good agreement with the three methods used in this investigation at all tested concentrations and that the acid extract of Mentha pulegium acts as green inhibitor for acid corrosion of carbon steel.

\section{Adsorption considerations}

Adsorption isotherm is necessary in studying the mechanism of adsorption and also the adsorption characteristics of the inhibitor.

In order to obtain the isotherm, coverage $\theta$ as a function of MPE concentration must be obtained being $\Theta$ is the ratio $\mathrm{E}(\%) / 100$. Several isotherms were tested, such as Langmuir, Temkin, Frumkin, etc., to well fit experiments data.

Fig. 3 shows the variation of $\Theta$ against the logarithm of the Mentha pulegium extract concentration. The data fit a straight line, with a slope nearly equal to unity, indicating that these compounds adsorb according to Temkin adsorption isotherm. The linear correlation coefficient is 0.993 , close to unity.

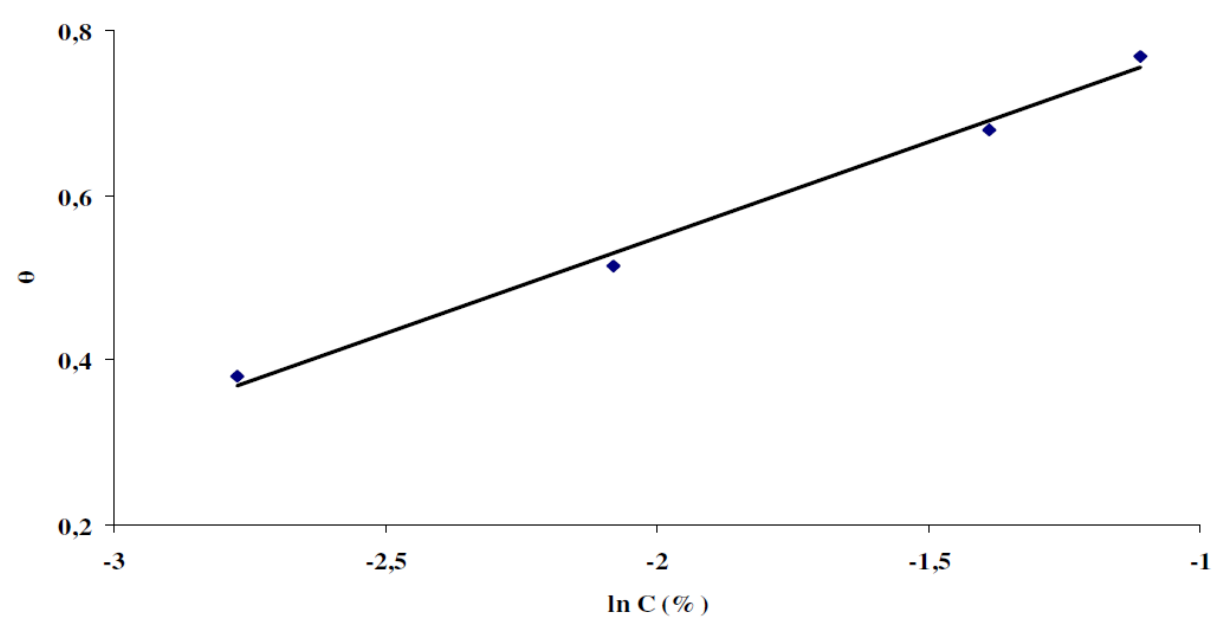

Figure 3. Plots of Temkin adsorption isotherm of Mentha pulegium extract on the carbon steel surface at $298 \mathrm{~K}$.

The Temkin isotherm equation is:

$$
\operatorname{Exp}(-2 a \cdot \theta)=K_{a d s} \cdot C
$$

where $\mathrm{C}$ is the Mentha pulegium extract concentration and $K_{a d s}$ the equilibrium constant of the adsorption process. 


\section{Effect of temperature}

The effect of temperature on the corrosion parameters of carbon steel in free and inhibited solutions of $1 \mathrm{M} \mathrm{HCl}$ was studied using weight loss measurements during 1 hour in the temperature range $308-338 \mathrm{~K}$; the corresponding results are summarised in Table 4.

Table 4. Effect of temperature on the carbon steel corrosion in the presence and absence of $33 \%$ of MPE at $1 \mathrm{~h}$.

\begin{tabular}{cccc}
\hline $\mathbf{T}(\mathbf{K})$ & $\mathbf{W}_{\mathbf{0}}\left(\mathbf{m g} / \mathbf{c m}^{\mathbf{2}} \mathbf{. h}\right)$ & $\mathbf{W}\left(\mathbf{m g} / \mathbf{c m}^{\mathbf{2}} . \mathbf{h}\right)$ & $\mathbf{E} \mathbf{( \% )}$ \\
\hline 308 & 0.3381 & 0.0626 & 81.62 \\
\hline 318 & 1.1464 & 0.2207 & 80.74 \\
\hline 328 & 4.0315 & 0.6920 & 82.84 \\
\hline 338 & 12.391 & 1.852 & 85.05 \\
\hline
\end{tabular}

The data in Table 4 indicate that the acid attacks were inhibited by addition of $33 \%$ of Mentha pulegium extract. But the increase in corrosion rate is more pronounced with the rise of temperature for the uninhibited acid solution. The presence of the inhibitor leads to decrease of the corrosion rate. E\% depends upon the temperature and increases with it.

\section{Activation energy calculations}

The change of the corrosion rate in presence and absence of $33 \%$ of Mentha pulegium extract was plotted against temperature for calculation of the activation energy (Fig. 4).

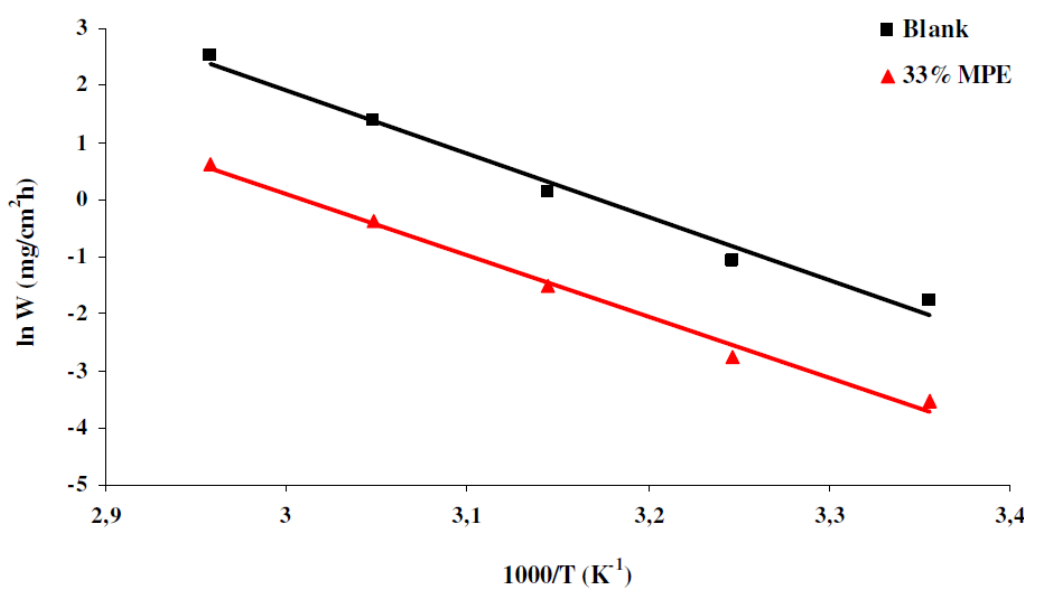

Figure 4. Arrhenius plots of carbon steel in $1 \mathrm{M} \mathrm{HCl}$ with and without $33 \% \mathrm{MPE}$.

The apparent activation energies (Ea) for the corrosion process in absence and presence of the inhibitor were evaluated from the Arrhenius equation:

$$
W=\mathrm{A} \cdot \exp \left(-\frac{E_{a}}{\mathrm{R} \cdot \mathrm{T}}\right)
$$

The effects of MPE increase the energy of activation and reduce the surface available for corrosion [27]. Addition of plant extracts at $33 \%$ in $1 \mathrm{M} \mathrm{HCl}$ decreases the activation energy from 92.41 to $89.32 \mathrm{~kJ} \mathrm{~mol}^{-1}$. This diminution may be attributed to the change in the mechanism of the corrosion process in the 
presence of adsorbed inhibitor molecules [28, 29]. The lower value of the activation energy of the process in the inhibitor's presence when compared to that in its absence is attributed to its chemisorptions [30-32].

\section{Scanning Electron Microscopy (SEM)}

SEM images were recorded to investigate the changes occurred on the surface of the carbon steel samples after $24 \mathrm{~h}$ immersion in $1 \mathrm{M} \mathrm{HCl}$ solution in the absence and presence of the inhibitor. Fig. 5 (a) presents the micrograph obtained for a carbon steel sample after exposure to blank solution, while Fig. 5 (b) presents the surface morphology of carbon steel specimens immersed in $1 \mathrm{M} \mathrm{HCl}$ medium containing 33\% of Mentha pulegium extract.
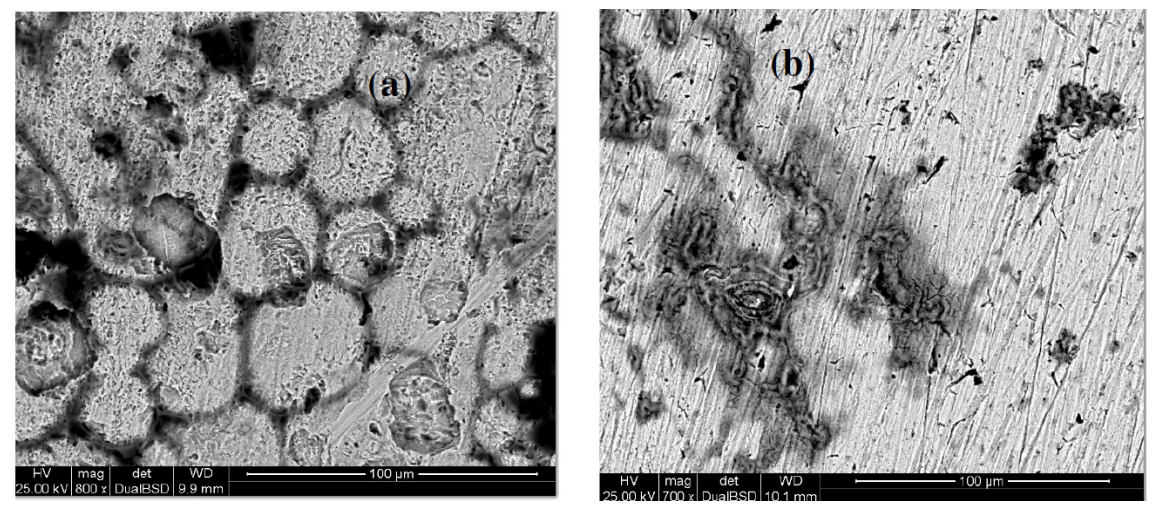

Figure 5. SEM images of carbon steel surface after $24 \mathrm{~h}$ immersion in $1 \mathrm{M} \mathrm{HCl}$ solutions in the absence (a) and presence (b) of 33\% MPE.

As can be seen from Fig. 5 (a), carbon steel surface in the uninhibited solution is severely damaged and rough due to an aggressive attack of the corroding medium. Fig. 5 (b) reveals that the corrosion marks on the inhibited samples decrease in presence of Mentha pulegium extract which also attests the inhibition ability and adsorption of the inhibitor on the carbon steel surface. Moreover the parallel lines on the carbon steel surface can be attributed to polishing scratches.

\section{Conclusion}

In this study, corrosion inhibition efficiency of Mentha pulegium extract (MPE), in $1 \mathrm{M} \mathrm{HCl}$ medium was determined by weight loss, potentiodynamic polarisation and electrochemical techniques. Results evidenced that this green inhibitor showed excellent performance (more than $88 \%$ at $33 \%$ ) as corrosion inhibitor. It inhibits through adsorption process and was found to follow Timkin adsorption isotherm.

Impedance studies revealed that the inhibitor reduced the corrosion rate by increasing the resistance of the system. Potentiodynamic polarization studies confirmed that the inhibitor acted through a mixed type of corrosion inhibition mechanism.

From SEM images, it can be deducted that the carbon steel surface became smoother in the presence of Mentha pulegium extract which had a positive effect on the corrosion properties of carbon steel. 


\section{References}

1. Khadraoui A, Khelifa A. Res Chem Intermed. 2013; 39: 937.

2. Khadraoui A, Khelifa A, Hamitouche H, et al. Res Chem Intermed. 2014;40:961.

3. Okafor PC, Ekpe UJ, Ebenso EE, et al. Bull Electrochem. 2005;21:347.

4. El-Etre AY, Abdallah M, El-Tantawy ZE. Corros Sci. 2005;47:385.

5. Khadraoui A, Khelifa A, Touafri L, et al. J Mater Environ Sci. 2013;4:663.

6. Oguzie EE, Onuchukwu AI, Okafor PC, et al. Pigment Resin Tech. 2006;35:63.

7. $\quad$ Ebenso EE. Mater Chem Phys. 2003;78:58.

8. Ebenso EE, Ekpe UJ, Umoren S, et al. J Corros Sci Technol. 2004;1:22.

9. Ebenso EE, Ekpe UJ, Umoren S, et al. J. Corros. Sci. Techol. 2004; 1: 96.

10. Oguzie EE, Okolue BN, Ogukwe CE, et al. J Corros Sci Technol. 2004;1:88.

11. Saleh RM, Ismail AA, El Hosary AH. Br Corros J. 1982;17:131.

12. Srivatsava K, Srivatsava P. Br Corros J. 1981;16:221.

13. Khadraoui A, Khelifa A, Boutoumi H, et al. Int. J. Electrochem. Sci. 2014;9:3334.

14. Putilova N, Balezin SA, Barannik VP. Metallic Corrosion Inhibitors. Oxford: London Pergamon Press; 1960.

15. Ammar IA, El Khorafi FM. Werkstsf \& Korros. 1973;24:702.

16. Abed Y, Kissi M, Hammouti B, et al. Prog Org Coat. 2004;50:144.

17. Khamis E, Al-Andis N. Mat-wiss u werkstofftech. 2002;33:550.

18. El-Etre AY. Corros Sci. 1998;40:1845.

19. El-Etre AY, Abdallah M. Corros Sci. 2000;42:731.

20. Parikh KS, Joshi KJ. Trans SAEST. 2004;39:29.

21. Sathiyanathan RAL, Maruthamuthu S, Selvanayagam M, et al. Ind J Chem Tech. 2005; 12:356.

22. Chetouani A, Hammouti B. Bull Electrochem. 2003;19:23.

23. Bouyanzer A, Hammouti B, Majidi L. Mater Letters. 2006;60:2840.

24. Kertit S, Hammouti B. Appl Surf Sci. 1996;93:59.

25. Tsuru T, Haruyama S, Gijutsu B. J Jpn Soc Corros Eng. 1978;27:573.

26. Benalli O, Larabi L, Traisnel M, et al. Appl Surf Sci. 2007; 253:6130.

27. Antropov LI. Corros Sci. 1967;7:607.

28. El Ouali I, Hammouti B, Aouniti A, et al. J Mater Environ Sci. 2010;1:1.

29. Bouklah M, Hammouti B, Lagrene'e M, et al. Corros Sci. 2006;48:2831.

30. Popova A, Christov M, Raicheva S, et al. Corros Sci. 2004;46:1333.

31. Chaieb E, Bouyanzer A, Hammouti B, et al. Appl. Surf. Sci. 2005;246:199.

32. Khadraoui, Khelifa A. Boutoumi H. et al. Nat Prod Res. 2014;28:1206. 